\title{
First report of Alternaria sp. causing blight on Incarvillea emodi
}

\author{
V. Shanmugam • D. Dhyani • D. Ananthapadmanaban
}

Received: 24 December 2009 / Accepted: 14 April 2011 /Published online: 24 May 2011

(C) Australasian Plant Pathology Society Inc. 2011

\begin{abstract}
During 2006-2009, a blight on Incarvillea emodi cultivated in Himachal Pradesh, India, was determined to belong to Alternaria sp. The disease occurred on leaves, twigs and flowers, and caused severe dropping of flowers during the cooler months, i.e., November-February. This is the first record of Alternaria sp. affecting $I$. emodi worldwide.
\end{abstract}

Keywords Alternaria sp. · blight · Incarvillea emodi

\section{Introduction}

Incarvillea emodi (Wallich ex Royle) Chatterjee, family Bignoniaceae is a flowering and foliage plant having potential ornamental and medicinal values; it is listed among the rare plants of Himalayan region (Singh and Sharma 2006). During cultivation in 2006-2009 (Fig. 1), the plants exhibited circular to irregular dark brown lesions (2-5 mm diameter) with greyish centre on leaves. Similar types of lesions appeared on twigs with sporulation. In flowers, the small brown lesions gradually coalesced to form a larger one covering $2 / 3$ rd of the flowers and ultimately the flowers withered and dropped (Fig. 2a-c). The disease symptoms were predominant during November-February

\footnotetext{
V. Shanmugam $(\bowtie) \cdot D$. Dhyani

Institute of Himalayan Bioresource Technology (CSIR),

Palampur 176061, Himachal Pradesh, India

e-mail: shanpatho@yahoo.com

D. Ananthapadmanaban

Microbial Type Culture Collection,

Institute of Microbial Technology (CSIR),

Chandigarh 160036, India
}

when the climate was cool $\left(15-20^{\circ} \mathrm{C}\right)$ and were less prominent towards the end of March.

Alternaria sp. was consistently isolated when sections of diseased twigs, leaf and flower were surface sterilised (2\% sodium hypochlorite), and plated on potato dextrose agar (PDA). Colonies reached up to $8.0 \mathrm{~cm}$ diameter in 7 days at

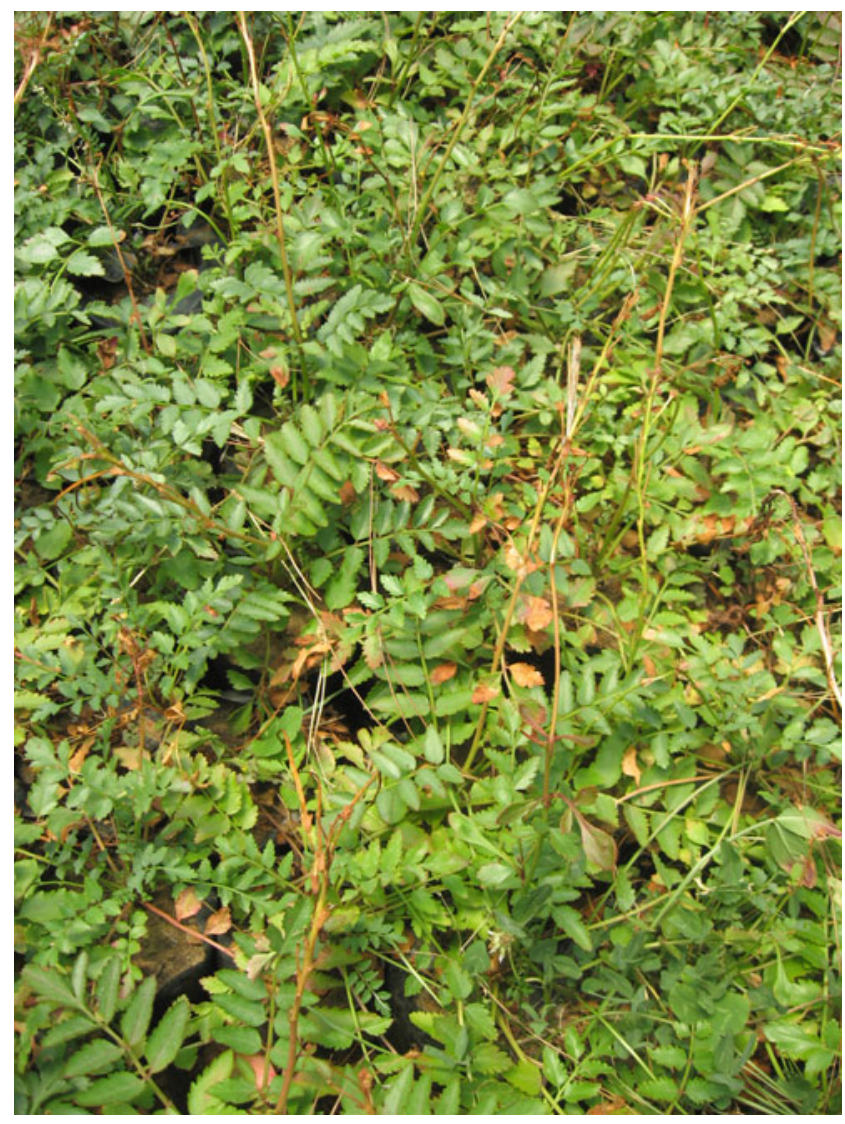

Fig. 1 Incarvillea emodi infected with blight disease 

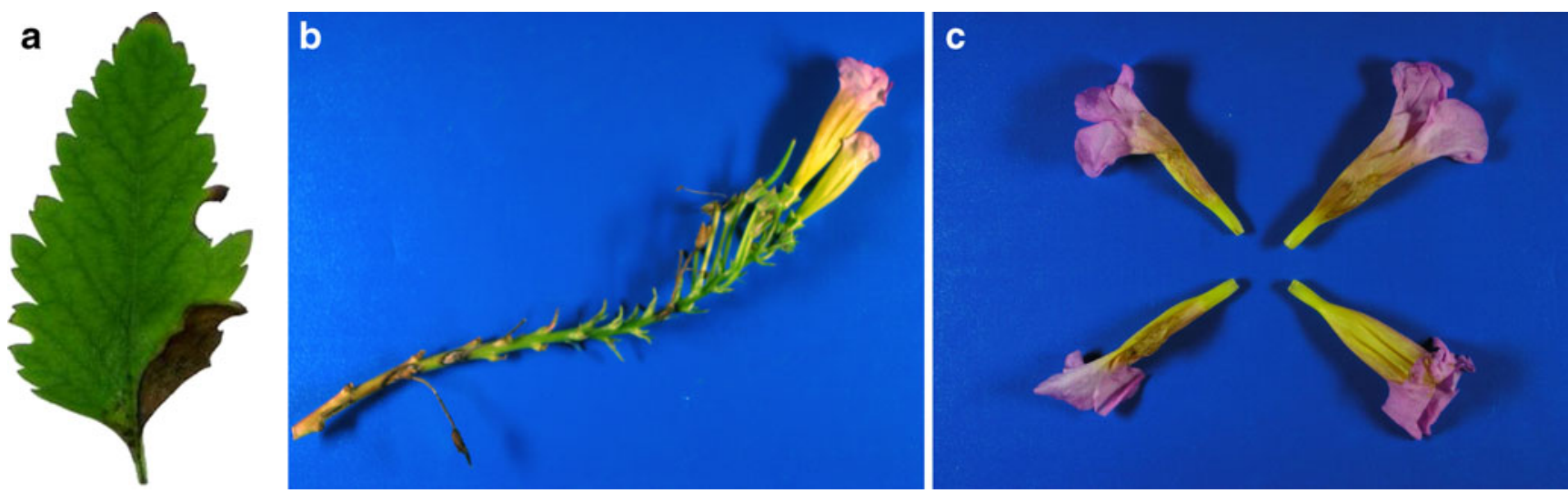

Fig. 2 Leaf blight symptoms on a leaf; $\mathbf{b}$ twig and $\mathbf{c}$ flowers

$25^{\circ} \mathrm{C}$ on PDA (Fig. 3) and potato carrot agar. Single-spore isolates were described based on morphological characters (Simmons 2007). Colonies effuse and black to olivaceous black, reverse dark black. Mycelium immersed to partly superficial, hyphae hyaline, olivaceous brown to brown. Conidiophores usually simple, straight or curved, arising singly or in small groups, conidiogenous cells integrated, terminal becoming intercalary, polytretic, sympodial or monotretic and cicatrized. Conidia formed in long, often branching chains, ovate, obclavate, obpyriform, or rarely ellipsoidal, with a conspicuous basal pore, with or without a short conical or cylindrical apical beak not exceeding one third of the conidial length, medium brown, smooth-walled or slightly verruculose, with up to eight transverse septa and usually several longitudinal or oblique septa, $18-63 \times$ 7-18 $\mu \mathrm{m}$ (Fig. 4). The culture has been deposited in the Microbial Type Culture Collection (MTCC 9601) of the Institute of Microbial Technology, Chandigarh, India. The species was placed in the A. alternata group but could not be more accurately identified based on conidial morphol-

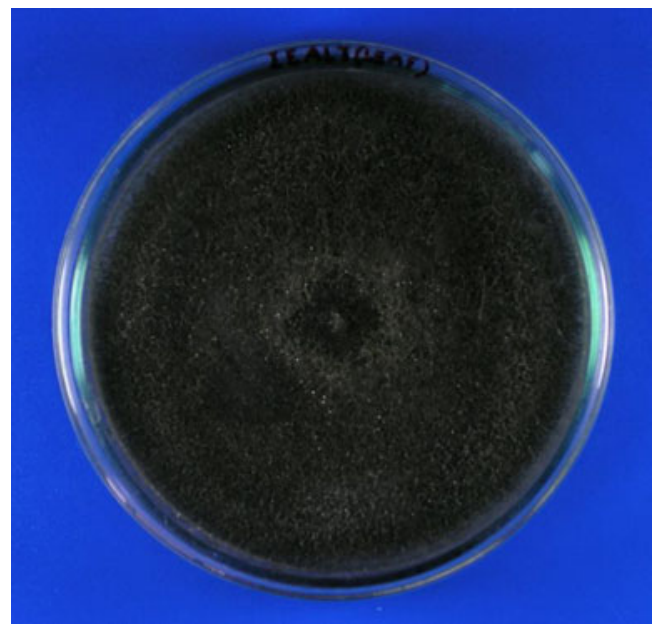

Fig. 3 Growth of fungal pathogen on PDA ogy. The rDNA ITS was sequenced (GenBank accession GQ121322) and was identical to sequences from many isolates of A. alternata and several other Alternaria species. Phylogenetic studies based on DNA sequences have been unable to resolve morphological species in Alternaria (Peever et al. 2004; Andrew et al. 2009).

Pathogenicity tests were done twice in a screen house by spraying a conidial suspension $\left(1 \times 10^{6}\right.$ conidia $\mathrm{mL}^{-1}$ in sterile tap water), obtained from 10 day old culture plates onto the healthy leaves of 10-month-old plants. Inoculated plants and water-sprayed controls were covered with polythene bags for $48 \mathrm{~h}$. Symptoms started developing on the inoculated leaves after $8-10$ days. The pathogen was reisolated from the leaves, twigs and infected flowers of affected inoculated plants to confirm Koch's postulates. The control plants did not exhibit symptoms.

Alternaria spp. infecting several hosts of ornamental and medicinal values have been reported e.g. Gerbera jamesonii (Mirkova and Konstantinova 2003), Stevia rebaudiana (Maiti et al. 2006), and Aloe barbadensis (Kamalakannan

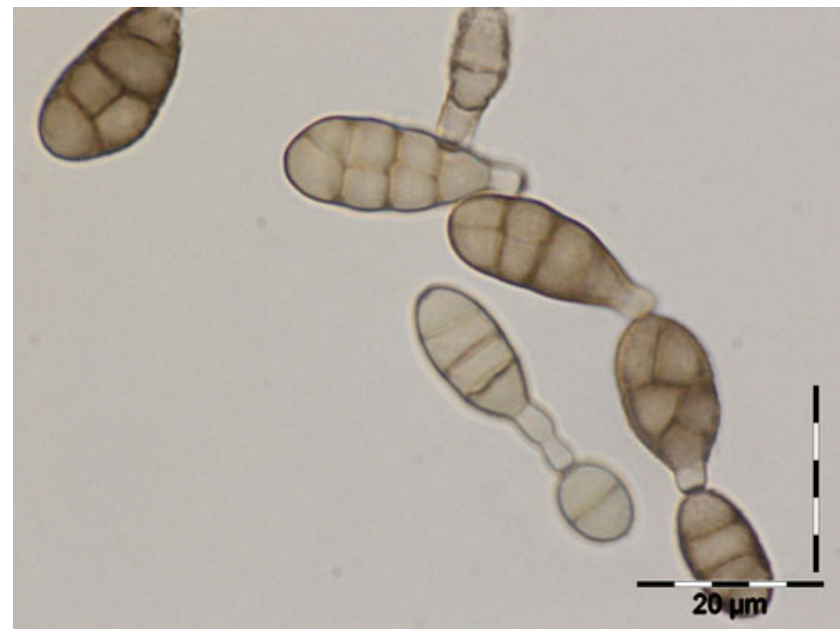

Fig. 4 Conidia of Alternaria sp.. Scale bar $=20 \mu \mathrm{m}$ 
et al. 2008). This is the first record of Alternaria sp. on I. emodi worldwide.

Acknowledgement We thank the Director, Institute of Himalayan Bioresource Technology, Palampur and Council of Scientific and Industrial Research for support and encouragement during the course of this investigation. IHBT Publication Number: 1007.

\section{References}

Andrew M, Peever TL, Pryor BM (2009) An expanded multilocus phylogeny does not resolve morphological species within the smallspored Alternaria species complex. Mycologia 101(1):95-109

Kamalakannan A, Gopalakrishnan C, Renuka R, Kalpana K, Ladha Lakshmi D, Valluvaparidasan V (2008) First report of Alternaria alternata causing leaf spot on Aloe barbadensis in India. Australasian Plant Dis Notes 3:110-111

Maiti CK, Sen S, Acharya R, Acharya K (2006) First report of Alternaria alternata causing leaf spot on Stevia rebaudiana. Available at http://www.bspp.org.uk/ndr/jan2007/2006-70.asp [Verified 31 July 2008]

Mirkova E, Konstantinova P (2003) First report of Alternaria leaf spot on gerbera (Gerbera jamesonii H. Bolux ex J. D. Hook) in Bulgaria. J Phytopathol 151:323-328

Peever TL, Su G, Carpenter-Boggs L, Timmer LW (2004) Molecular systematics of citrus-associated Alternaria species. Mycologia 96 (1):119-134

Simmons EG (2007) Alternaria. An identification manual. (CBS Biodiversity Series 6. 775pp. 288 figs).

Singh H, Sharma M (2006) Flora of Chamba District (Himachal Pradesh). Bishen Singh and Mahindra Pal Singh Publishers, Dehradun 